\title{
O DEBATE EDUCATIVO NACIONAL NO DISCURSO DOS INTELECTUAIS DO DIÁRIO DOS CAMPOS (1907-1928)
}

\author{
Eliezer Felix de Souza ${ }^{1}$ \\ Universidade Estadual de Ponta Grossa - UEPG \\ eliezer.felix@hotmail.com \\ Névio de Campos ${ }^{2}$ \\ Universidade Estadual de Ponta Grossa - UEPG \\ ndoutorado@yahoo.com.br
}

\section{RESUMO:}

O presente artigo tem como objetivo a análise da recepção dos debates nacionais sobre educação no discurso dos intelectuais do jornal Diário dos Campos, Jacob Holzmann, Hugo de Borja Reis e José Cadilhe no período estudado e compreendido entre 1907 e 1928. Essa discussão apoiou-se no conceito de intelectual como organizador da cultura gramsciniana e na concepção de discurso do círculo de Bakhtin. Pela análise feita evidencia-se que os intelectuais do referido periódico apresentavam em seus discursos várias temáticas: missão da educação, a tese da educação feminina e formação de professor, bem como a defesa de reformas educativas. Com base na documentação analisada é possível indicar que o grupo estabeleceu interlocução com as discussões educativas promovidas nas principais cidades brasileiras e reafirmou o discurso salvacionista da educação para combater o analfabetismo.

Palavras-chave: Educação. História. Intelectuais. Imprensa.

\section{NATIONAL EDUCATIONAL DEBATE IN THE SPEECH OF INTELLECTUAL DIARY OF FIELDS (1907-1928)}

\begin{abstract}
This article aims to analyze the reception of national debates on education in the intellectual discourse of the newspaper Diario dos Campos, Jacob Holzmann, Hugo Borja Reis and Joseph Cadilhe during the study period and between 1907 and 1928. This discussion has relied on the concept of intellectual culture as an organizer gramsciniana and designing speech by the Bakhtin circle. For the analysis shows that the intellectuals of that journal had several themes in their speeches: the mission of education, the idea of female education and teacher training, and advocacy of educational reforms. Based on the documentation reviewed is possible to indicate that the group established communication with the educative discussions promoted in major Brazilian cities and reaffirmed Salvationist discourse of education to combat illiteracy.
\end{abstract}

Keywords: Education. History. Intellectuals. Press.

\section{Introdução}

Este artigo tem como objetivo principal analisar a recepção dos debates nacionais sobre educação no discurso dos intelectuais do Diário dos Campos $^{3}$ no período compreendido entre 1907 e 1928. Nesse período, atuaram no jornal Jacob Holzmann, Hugo de Borja Reis e José Cadilhe que, além de editores foram proprietários do referido 
periódico. Com exceção de Hugo Reis, a maioria dos artigos não foram assinados por esses intelectuais. Entretanto, enquanto editores do jornal, defendemos a hipótese de que tiveram autonomia para autorizar ou impedir a circulação desses discursos.

Jacob Holzmann foi alfaiate, regente da banda Lira dos Campos, comerciante e, entre outras atividades, sua maior atuação se deu no campo cultural, com a fundação de teatro, regente da banda Lira dos $\mathrm{Campos}^{4}$, e uma posição de maior destaque com a fundação do jornal O Progresso em 1907. Como Maestro viveu momentos de grande repercussão no cenário social ponta-grossense. Em seu jornal manifestou-se em vários momentos e como proprietário pôde, por várias vezes, expressar suas opiniões, uma vez que sempre se preocupou com o jornalismo e a cultura geral de Ponta Grossa, apesar de que no jornal não ter ele próprio pronunciado discursos em relação à educação.

Hugo Reis chegou a Ponta Grossa em 1908 e era experiente no campo do jornalismo, além de ter uma postura literária plural. Suas referências constatam que exerceu o papel jornalístico no Rio de Janeiro e em São Paulo com grande desempenho. Como editor lançou o "Manifesto" para a fundação da Sociedade Operária de Ponta Grossa e no campo religioso foi doutrinador espírita de méritos inconfundíveis. Em seus discursos divulgou a doutrina Espirita e defendeu o combate ao analfabetismo como uma missão da imprensa.

José Fernandes Cadilhe foi editor do jornal a partir de 1921 e teve uma influência marcante no jornalismo ao atuar no Diário dos Campos. Apesar de não aparecer nenhum texto sobre educação escrito por ele, foi no período da sua atuação como editor que foram destacadas as reformas educacionais do governo Caetano Munhoz da Rocha. As trajetórias desses homens tiveram contribuição relevante no processo de formação da opinião e da organização da cultura no início do século XX na cidade de Ponta Grossa.

O jornalismo ponta-grossense surge atrelado a alguns fatores de modernização que a cidade passava a conquistar. A origem do Diário dos Campos remonta-se a 1904 quando foi fundado o jornal $O$ Comércio. Esse jornal foi comprado por Jacob Holzmann, em 1907 e transformado em $O$ Progresso. Inicialmente, o jornal começou a ser editado semanalmente. Em 1908, no entanto, passou a circular três vezes por semana. Em janeiro de 1913, "O Progresso" passou por um período de transformações, tendo seu nome mudado para "Diário dos Campos", com tiragem diária. Desse espaço cultural os intelectuais discutiram os problemas da sociedade e da educação brasileira, paranaense e ponta-grossense.

À luz dos conceitos de cultura e intelectuais postulados por Gramsci defendemos que tais jornalistas dialogaram com as ideias educativas que circulavam na imprensa nacional, apropriando-se de muitos aspectos para trazer à baila problemas específicos da educação paranaense. Este texto insere-se na perspectiva da história intelectual e da história intelectual da educação. Nesse aspecto, cabe-nos fazer duas considerações: a primeira sobre a História Intelectual da Educação e a segunda em relação à História Intelectual propriamente dita.

No primeiro aspecto a constituição de grupos de pesquisa sobre a História intelectual da Educação é recente e, vem ocorrendo nos programas de Pós-Graduação em Educação das instituições de ensino. No Estado do Paraná, por exemplo, merece menção o Grupo de Pesquisa em História Intelectual da Educação coordenado por Carlos Eduardo Vieira, professor da Universidade Federal do Paraná. A preocupação desses pesquisadores é "[...] pensar as idéias, as representações e/ou discursos veiculados no debate intelectual, a partir dos seus contextos de produção, de circulação e de recepção." (VIEIRA, 2007, p. 9).

Com relação à História Intelectual dialogamos com Helenice Rodrigues da Silva que afirma que "domínio novo e mal definido, a História Intelectual transformou-se, nas 
últimas décadas, em estimulante objeto de investigação.” (SILVA, 2003, p. 15). Em síntese, a História Intelectual tende a apresentar-se sob a forma de uma história dos intelectuais ou de uma história das ideias e abrange a participação de um intelectual na sua relação com o seu espaço e os sujeitos sociais que o circundam e possibilita diferentes enfoques, como por exemplo, o contexto de produção de ideias, o dos agentes sócioprofissionais e das correntes de pensamento.

No horizonte teórico da História Intelectual um dos debates se refere ao conceito de intelectual discutido por Antônio Gramsci. Em suas análises, esse pensador distingue a intelectualidade tradicional, considerada classe ou comunidade à parte, e os grupos que as classes produzem organicamente a partir das suas relações. Essas novas classes exercem funções predominantemente intelectuais e fazem parte de instituições ligadas à atividade cultural. O elemento fundamental oriundo das reflexões de Gramsci consiste em reconhecer que os intelectuais não constituem camadas externas às lutas políticas, sociais e culturais. Ao contrário, o intelectual se caracteriza pelo imiscuir-se nas diferentes esferas da vida societária. E uma dessas esferas é o jornalismo que, no mundo moderno, passou a exercer um espaço profícuo no processo de constituição de novos modos de pensar, de agir, de sentir e de ser. O que é relevante da discussão de Gramsci é a atribuição dada aos intelectuais, qual seja: de organizadores de visões de mundo e mobilizadores dos indivíduos em prol de projetos políticos, sociais e culturais.

Nas primeiras décadas do século XX, a presença dos intelectuais em espaços públicos ganhou maior evidência, particularmente pelo processo de expansão da imprensa escrita. Ciente da importância do uso das fontes impressas para a pesquisa em história é importante salientar que "o debate em relação ao uso dos impressos periódicos ganhou especial destaque nas últimas décadas do século passado." (MARTINS; LUCA, 2008, p. 13). A imprensa começou a ter um papel de destaque na vida social, principalmente no período que marcou a passagem do século XIX para o século XX. Momento marcado pelas transições da pequena à grande imprensa nos principais centros urbanos brasileiros. Sua atuação passou a traduzir as novas ideias e hábitos gerados pelas transformações vivenciadas pela população, tornando-se o espaço privilegiado para a discussão dos principais problemas sociais dentre os quais a educação publica.

No artigo intitulado "História dos, nos e por meio de periódicos", Tânia Regina de Luca faz alguns apontamentos a respeito de pesquisas com periódicos. De modo geral, fica perceptível que, até a década de 1970, ainda eram raros os trabalhos que se valiam de jornais e revistas como fonte para o conhecimento da História. Porém, já desde 1930, a Escola dos Annales já havia lançado as bases de novas perspectivas de pesquisa com a imprensa tendo como pressuposto a mudança da concepção que esta escola teve em relação ao documento. Com isso os adeptos da Escola dos Annales passariam a reconhecer a relevância dos meios impressos nas pesquisas históricas, no entanto, a utilização dos periódicos como fonte só ocorreria pela intermediação da terceira geração ${ }^{5}$ dos Annales. Estes proponentes lançaram novas perspectivas para as análises históricas cujas temáticas passavam a incluir "o inconsciente, o mito, as mentalidades, as práticas culinárias, o corpo, as festas, os filmes, os jovens, as crianças, as mulheres, aspectos do cotidiano, enfim uma miríade de questões antes ausentes do território da História." (LUCA, 2005, p. 113).

Essa renovação temática abriu consideravelmente as possibilidades de fontes para as pesquisas em História. Além da abrangência das fontes para pesquisas, abriram-se também novas perspectivas analíticas. Os marxistas, sobretudo E. P. Thompson seguiram na ideia de escrever uma história pela ótica dos vencidos. Assim, sair-se-ia daquela visão positivista que se baseava em documentos oficiais para escrever a história dos heróis e das grandes personalidades. Além da abordagem marxista, outro aspecto importante foi o 
desenvolvimento das chamadas "História Cultural", "História imediata" e "nova história política". Essas inovações no campo historiográfico trouxeram perspectivas abrangentes para o estudo da história. Após um amplo debate a partir da década de 70, o jornal tornouse fonte de pesquisa histórica em longa escala.

Carlos Eduardo Vieira (2007b), ao tematizar a imprensa, analisa essa questão no âmbito nacional e paranaense. Com relação ao Paraná, o autor referencia a atuação dos jornais Diário da Tarde e a Gazeta do Povo, fundados em 1899 e 1919, respectivamente. Esses jornais tiveram papel de destaque na esfera política, social e aderiram também à causa educacional. Já em nível nacional, Vieira enfatiza o jornal O Estado de São Paulo que teve atuação relevante na causa educacional, sobretudo na década de 1920. Nesse período, Fernando Azevedo lançou os famosos inquéritos sobre educação e, a partir deles resultaria em 1932 a publicação do Manifesto dos Pioneiros da Educação Nova.

Ao utilizar os periódicos apontados acima Carlos Eduardo Vieira afirma ainda que "enfocaremos o jornal como fonte e como objeto de pesquisa, uma vez que exploraremos suas potencialidades como documento, como suporte de sentidos, bem como seu protagonismo como agente social." (VIEIRA, 2007b, p. 14). Compartilhamos da sua posição quando afirma que "o jornal impresso diário é parte de uma estrutura midiática de enorme impacto e, cada vez mais, diversificada ação política e cultural.” (p. 15). Ele pode ser "[...] entendido como lugar de produção, veiculação e circulação dos discursos assume uma função importante no processo de formação das representações sobre o mundo." (p.16).

Com base nessas observações, partimos da hipótese de que os intelectuais pontagrossenses filtraram e atribuíram um sentido fundamental às ideias educativas que circulavam nas principais capitais do Brasil. Utilizando-se da orientação metodológica do Círculo de Bakhtin que aponta que "o ser, refletido no signo, não apenas nele se reflete, mas também se refrata" (BAKHTIN; VOLOSHINOV, 2002, p. 46), explicitamos que Bakhtin, ao tratar da linguagem verbal, afirma que a verdadeira substância da língua é a interação verbal. Isso porque é possível compreender a palavra 'diálogo' não apenas como comunicação, em voz alta, de duas pessoas colocadas face a face, mas toda a comunicação verbal, de qualquer tipo que seja. Ou seja, apesar de não apresentar uma metodologia explícita, Bakhtin e os autores de seu círculo nos indicam que o discurso humano é dialógico, mesmo que seja resultado de uma pesquisa individualizada, pois, de certa forma, o texto é uma produção coletiva, uma vez que sofre a interferência de ideias de muitos agentes sociais. Da mesma forma o jornal - um diálogo entre jornalistas (intelectuais), leitores e o contexto como um todo.

Os intelectuais de Ponta Grossa preconizaram debates sobre um conjunto de temáticas candentes nas primeiras décadas do século XX. Na avaliação dos escritores do Diário dos Campos, era necessário investir no processo de constituição de reforma social, urbana, cultural e educacional na cidade de Ponta Grossa. Era comum se apregoar a premência de se modernizar a cidade, cobrando investimento na criação de serviços de saneamento, industrialização, iluminação e instrução pública. Os discursos dos intelectuais faziam forte crítica ao índice de analfabetismo existente no Estado do Paraná, por consequiência na cidade de Ponta Grossa. No jornal Diário dos Campos o discurso educacional ganhou contornos diversos - no qual os enunciados sobre missão da educação, educação da mulher, formação de professores e reformas educacionais tiveram prevalência.

\section{Educação do homem - completo saneamento moral da sociedade}

O início do século XX no Brasil foi marcado pela presença da intelectualidade 
brasileira que participou do debate em torno da modernização do país, dos ideais republicanos e principalmente da educação do povo brasileiro. Os intelectuais do Diário dos Campos participaram desse debate e em seus discursos evidencia-se a necessidade educativa atrelada a outros problemas sociais. Por exemplo, a edição $\mathrm{n}^{\circ} 243$ de 04 jan.1910, numa matéria intitulada "o Policiamento da Cidade", assinala-se que "[...] as conseqüências de fatos, registrados diariamente, no comissariado da polícia desta cidade não viríamos reclamar, em nome da civilização da moralidade de um povo contra o que se pratica [...]." É a criminalidade que começou se tornar rotina na cidade e fez com que o discurso fosse esse: "há momentos em que o foro de cidade civilizada, de que goza a fulgurante Estrela dos Campos Gerais deixa de ser o privilégio de um povo adiantado e culto."

Ao abordar essa temática, Carlos Monarcha (1999, p. 75) afirma que no final do século XIX "popularizam um vocabulário específico "-civilização-", "-razão-", "progresso-", "-constituição-", “-soberania-" - e acima de tudo, a palavra "-luz-"." E "tal discurso oscila entre imagens catastróficas - criminalidade, alcoolismo, decadência moral, social e política e imagens redentoras - civilização/progresso, bem-estar. Confrontam a presença de uma sociedade decaída e a confiança numa sociedade redimida." (p. 75). Mas, se num primeiro plano a violência e o crime exigiam a instauração de instituição repressiva (a organização da polícia urbana de São Paulo ocorre em 1876), era necessário estabelecer também uma política de caráter persuasivo - a instrução pública. Porque é "pela instrução que conhece o homem a importância da responsabilidade moral, o encanto e a vantagem do trabalho; e a responsabilidade é o mais fecundo freio dos crimes, e o trabalho é o mais fecundo elemento da civilização humana em todo sentido." (p. 81).

Esse contexto analisado por Monarcha pode ser aproximado do discurso do jornal que apresenta a criminalidade como atos de povos incivilizados, cuja principal solução seria a educação que aparecia na condição de salvadora da sociedade, funcionando como completo saneamento moral da sociedade. A posição discursiva apresentada no jornal é que,

[...] não deixaremos de reclamar a droga salvadora para combater a enfermidade, já que nos falta o principal - o completo saneamento moral da sociedade, pela educação do homem. Aplique-se, outro remédio - o lembrado pela cirurgia moral - a neutralisação do mal na parte afetada, pela amputação do membro. (O PROGRESSO, ed. 243, 04 jan. 1910).

Está claro que existiam problemas na sociedade ponta-grossense, e o autor do texto, ao mesmo tempo, aponta a solução para o mal, a saber: a educação do povo. Ela aparece como uma maneira profilática de evitar muitos males sociais. Esse discurso salvacionista presente nessa passagem citada do jornal foi debatido nas conferências da Associação Brasileira de educação a partir de 1927. Segundo Marta Maria Chagas de Carvalho,

[...] o discurso cívico da $\mathrm{ABE}$ é discurso profilático erigindo a questão sanitária em metáfora da situação nacional e a obra educacional em obra de saneamento. Na já aludida conferência de Miguel Couto na ABE, em 1927, a ignorância é caracterizada como "calamidade pública" equivalente à "guerra", à "peste", a "cataclismos"; a falta de educação é comparada ao "câncer que tem a volúpia da tortura ao corroer célula a célula, fibra por fibra, inexoravelmente, o organismo", levando a nação à "subalternidade e à degenerescência". (CARVALHO, 1998, p. 145).

Esse discurso profilático já fazia parte do novo ideal republicano no qual a 
instrução popular aparecia como uma semântica salvadora. Esse sentido pode ser observado também na edição 293 de 02 agosto de 1910 do jornal O Progresso com o título "O Analfabetismo": "Filantropos sociais, respondei-me a isso: as vossas estatísticas dizem: a instrução diminui a perversão, quer dizer - o alfabeto diminui o crime. O crime é uma doença da alma, como a pneumonia é uma doença dos pulmões." Ao analisar o problema como uma doença, a possível solução seria: "para a doença há um remédio, e para o envenenamento há um antídoto. Acotovelando o com uma escola. O professor há de eliminar o carcereiro." E prosseguindo, "mas considerando que se a sociedade tivesse fornecido um $\mathrm{ABC}$ ao ignorante e um ofício ao mendigo, a soma da ignorância com a miséria não produziria - o crime." $O$ discurso é enfático ao afirmar: "condenamos a sociedade a que dê instrução a todas as crianças e dê trabalho a todos os famintos aplicando se mais a evitar o assassinato do que a regenerar os assassinos."

Conforme Monarcha "sob a estatística das escolas, decresce a estatística do pauperismo e do crime. Isto, porém, consegue-se procurando que o mínimo de educação não fique abaixo da instrução que todo o homem deve possuir para compreender os seus deveres e vindicar os seus direitos." (MONARCHA, 1999, p. 82). A educação teria uma missão salvadora, regeneradora da civilização. É nessa direção que se buscava implementar medidas de políticas públicas que tinham como finalidade combater o analfabetismo. Mais uma vez a sociedade era comparada a uma doença que precisava ser sanada, sendo a escola o seu principal remédio. Mas só ela não era o essencial, sendo preciso ainda dar atenção ao professor. Utilizando-se destes mecanismos, o autor do texto se mostrou um tanto quanto otimista, porque a propagação da instrução evitaria o crime e o assassinato.

Ainda na continuação do texto "Analfabetismo", na edição 293 de 02 agosto de 1910, Guerra Junqueiro discorre sobre a felicidade: "A felicidade! Em que consiste essa illusão? No amor? Na saudade? Na riqueza? De que serve que um homem encontre todas essas fortunas invejadas se para cada homem que as possui há um milhão de homens que as não tem?!" Ou seja, a preocupação central do artigo era o combate ao analfabetismo. Suas interrogações continuam: "Enquanto pessoas dormem no conforto do lar, muitas outras mendigam nas praças da cidade, à porta da igreja, nas esquinas. Mas de onde veio esse indivíduo? De onde surgiu?" Nessas indagações, o autor indicava alguns possíveis fatores que determinaram essa posição social negativa.

[...] $\mathrm{Na}$ época em que as crianças roubam ninhos, ele roubava relógios. Precodiade.

Quando os outros eram anjos, já ele era gatuno. Na idade em que se aprende a ler, ele aprende a assobiar.

Os preconceitos e os crimes buscam os cérebros analfabetos, como os morcegos e os chacais buscam os subterrâneos às escuras.

Não teve mãe, não teve pai, não teve berço, não teve escola. Germinou como um tortulho venenoso. A alma ensangüentada da miséria tem dessas gerações espontâneas. (O PROGRESSO, ed. 293, 02 ago. 1910).

A preocupação dos enunciados refere-se ao combate ao analfabetismo. No início do século XX era recorrente a entonação discursiva em defesa da alfabetização do povo brasileiro. Aurélio Bona Júnior e Carlos Eduardo Vieira, ao abordar o discurso da modernidade nas conferências educacionais da década de 1920 no Paraná, afirmam que "os principais objetivos dos fóruns educacionais, segundo seus organizadores, eram discutir e propor alternativas aos problemas nacionais que, segundo a crença da época, poderiam ser sanados pela obra educativa." (2007, p. 22). 
Concentrados na força da educação, "[...] a falta de instrução do povo foi apontada como uma das causas do descompasso do país em relação ao concerto das nações modernas." (BONA JÚNIOR; VIEIRA, 2007, p. 23). Os mesmos autores mais adiante afirmam que "o índice de analfabetismo figurava como a principal evidência da ignorância do povo e foi incorporada aos discursos políticos e educacionais ao longo do século XX em distintos contextos." (p. 23-24). Apesar de tudo, "os altos índices de analfabetismo não foram apresentados como resultantes da incompetência das elites políticas em promover a educação popular, mas sim pela resistência destas camadas da população em entender os papéis da escola e da educação no desenvolvimento da sociedade brasileira". (p. 24).

Hugo Reis, na edição n” 623 de 17 de outubro de 1912, no artigo intitulado "Guerra ao Analfabetismo" explicita sobre a semântica do título.

O notável projeto que demos circunstância detalhes nestas colunas, visando remover da nossa face, como nação civilizada e depositária de uma boa porção da intelectualidade latina, o ferrete ${ }^{7}$ ignominioso da escravatura da alma, - o analfabetismo, teve repercussão na pátria de Tiradentes, naquella terra alterosa, que José Bonifácio, o venerável chamou de "estrela brilhante do sul, formosa província de Minas.

Reis referencia em seu discurso as transformações educativas que estavam sendo formuladas em Minas Gerais que, segundo o texto, teve a inspiração vinda de homens como Tiradentes e José Bonifácio. No Estado do Paraná, o exemplo citado é José Correa de Freitas. Na visão do autor, o "nosso grande Correa" foi um dos principais representantes pela integração dos debates relacionados à questão do analfabetismo.

Hugo Reis afirma ser responsabilidade da imprensa, lançar no seu primeiro congresso, os debates intitulados a "A guerra contra o analfabetismo". Essa ação seria um dos aliados mais importantes na luta pelos "nossos indigentes intelectuais." (O PROGRESSO, ed. 623, 17 out. 1912). No artigo intitulado "Imprensa a serviço do Progresso", Maria de Lourdes Eleutério (2008) analisa a atuação da imprensa na Primeira República (1889-1930), e aponta que alfabetização, na concepção republicana, era um fator essencial para a transformação da nação. Para os jornalistas, essa temática era também importante, uma vez que ela estava relacionada à formação do leitor. Nos periódicos da época, os leitores encontraram suporte preferencial para o exercício da leitura e das letras. Observa-se, por essa tendência apontada por Maria de Lourdes Eleutério, que Hugo Reis estava não só vinculado aos princípios republicanos de transformação social, como seguia também as linhas editoriais dos grandes jornais brasileiros.

Nos discursos republicanos o que predominou efetivamente foi uma fé imensurável nas potencialidades humanas que poderiam ser aperfeiçoadas pelo desenvolvimento da instrução pública. A visão da época, em relação à educação, era que a instrução pública era uma das principais vias pela qual se efetivariam as aspirações, ao mesmo tempo em que se configuraria numa experiência histórica que se propunha a realizar a felicidade do povo. Pela análise que fizemos até aqui percebemos que a educação tinha como missão combater o analfabetismo e instituir medidas públicas para a educação da sociedade.

\section{A mulher na educação da mocidade é preciosa no terreno da pedagogia moderna}

Nesta categoria, tomamos como ponto de partida analítica a transcrição da fala de Annita Philipowiski ${ }^{8}$. Em entrevista concedida a Raul Gomes ela afirma:

Nós moças de Ponta Grossa, que fontes tivemos e temos para saciar nossa 
sede de saber? Em uma escola de primeiras letras recebíamos o ensino das matérias elementares, e este mesmo interrompido pelos impedimentos da professora, e nada mais. [...] A Escola Normal prepara as moças especialmente para professoras, porém poucas são as que têm vocação e a indispensável dedicação para a carreira, e por este motivo vem a ser, quase todas, mestras bem medíocres. Quando se abriu o instituto "Dr. João Candido", em nossa cidade podia estabelecer se também um curso secundário para meninas ensinando com especialidade geografia geral, eletricidade, escrituração mercantil, contabilidade, taquigrafia e uma das línguas mais geralmente faladas como a francesa, inglesa ou alemã. Ficariam, com o preparo nessas matérias, habilitadas para ocuparem cargos no correio, telegrafo telefone, ou como guarda livros e correspondentes comerciais. [...] Seria prematuro reclamar universidades ou academias no Paraná onde se salientassem mulheres como Mme. Curie Lente da Sorbonne, Luiz e Jacobsen na Dinamarca, Anna Rogstad membro do Parlamento na Noruega e ultimamente até uma secretaria da legação, Clotilde Luici, nomeada pelo Governo do Uruguay para a respectiva legação em Bruxellas. (O PROGRESSO, ed. 595, 08 ago. 1912).

O pensamento de Annita Philipowiski é adiantado em relação a sua época. Ela comenta sobre a fragilidade da escola de primeiras letras destinada às mulheres e afirma que poucos pais podiam financiar o curso secundário na capital. Com isso, a única alternativa apontada por ela refere-se à Escola Normal que naquele contexto somente existia em Curitiba. Essa escola Normal, por sua vez, oferecia curso de formação de professores, mas segundo Philipowisli, eram poucas as mulheres que tinham vocação para esta função, por isso, embora cautelosamente, assinalava para a implantação de novos espaços de formação, como universidades e academias, pois no entendimento da entrevistada era necessário a existência de uma disposição vocacional para ser professora. Além disso, Philipowiski, não deixa de lamentar a falta de uma escola secundária para as mulheres na cidade, embora naquele momento também não existisse ensino secundário público para os homens em Ponta Grossa.

Etelvina Maria de Castro Trindade, em Clotildes ou Marias: mulheres de Curitiba na primeira República analisa a educação feminina. Nessa obra utiliza como fonte básica a imprensa periódica. Os objetivos principais traçados pela autora baseavam-se na investigação do pensamento, compreensão da educação, conhecimento da cidade e redescoberta das mulheres. Segundo Trindade, "as primeiras décadas da República no Brasil foram marcadas pela necessidade de consolidar o novo regime, fazendo surgir uma série de estratégias que a mulher não está absolutamente alheia." (TRINDADE, 1996, p. 13). No entendimento da autora "educada para o mundo interior, é uma mulher solicitada a dar contribuição externa que inclua tanto o desembaraço e a efusão, quanto o recato e a modéstia." (p. 14).

No discurso do jornal:

Quando em uma escola, encontrardes creanças bem educadas; quando na sociedade, encontrardes homens bastante polidos, podeis asseverar de antemão que foi uma boa e inteligente mãe quem lhes guiou os primeiros passos e quem lhes abriu cuidadosamente a pratica da moral. (O PROGRESSO, ed. 246, 11 jan. 1910).

Nesse discurso a função principal da mulher "educada" seria para que ela tivesse 
condições de educar seus filhos. Nos objetivos identificados por Trindade, essa condição permaneceu intocável. Com relação à educação da mulher: "que se pretende da menina? Que seja o anjo velador do lar, a carinhosa promotora da educação da família." (TRINDADE, 1996, p. 32). Conforme aponta a autora, “[...] a República vê na mulher e em seu corpo a matriz das futuras gerações: mas entende, por outro lado, que a mãe só preenche plenamente sua função sendo aquela que educa;” (p. 35), porém, já se preconizam possibilidades para que se ampliem o espaço de sociabilidade das mulheres.

Trata-se da profissionalização da mulher que começa a desenvolver-se nos países europeus. O artigo intitulado "O talento das mulheres", (O PROGRESSO, ed. 276, 23 jun. 1910), traz em seu conteúdo um discurso que relativiza a dominação masculina e tem como contexto as transformações femininas européias. Divulga-se representativamente o surgimento de uma mulher de participação mais ativa na vida pública. $\mathrm{O}$ texto é transcrito desta forma:

\begin{abstract}
Nos países em que a educação moral da sociedade cercou a mulher de respeito, garantiu a contra a insensatez sensual do macho, deu-lhe, em pé de igualdade, o direito de sentar-se nos mesmos bancos acadêmicos que ocupavam sozinhos os homens - ela começou a desenvolver os seus talentos, a disputar a vitória no struggle for life e a ser se não competidora, colaboradora preciosa dele na obra da civilização. (O PROGRESSO, ed. 276, 23 jun. 1910).
\end{abstract}

Na passagem fica clara a divulgação de um novo ideal de mulher. Elas que estavam submetidas a uma vida enclausurada, doméstica, começavam a ter participação mais destacada na vida social pública. Essa condição deve ser olhada com muita cautela, pois o autor do texto assume uma postura temerosa em relação à emancipação feminina. Para isso, basta observarmos a sequência do texto em que são descritos os novos cargos ou funções ocupadas pelas mulheres no velho mundo:

No comercio, a atividade feminina está começando a criar uma situação difícil para o homem. Capaz de administrar a sua vida com mais economia e maior conforto que seu rival; mais delicada e flexível e com um desenvolvimento senso artístico nativo, assim habilitada a produzir trabalho mais barato, nítido, acurado e rápido - a datilografa, a telegrafista, a caixeira, a enfermeira, a servente de laboratório, em regra desloca o homem e toma-lhe o lugar. (O PROGRESSO, ed. 276, 23 jun. 1910).

A mulher é apresentada com maior eficiência que o homem. Ao mesmo tempo em que sua mão-de-obra "é mais barata que o masculino". O que se percebe por essas duas passagens é um novo espaço social que a mulher passa a ocupar. A mulher que permanecia até então num espaço predominantemente familiar passa a ter visibilidade pública e começa a preocupar ao homem. No final do século XIX, sua presença começou a ser percebida em lojas e no universo do trabalho como um todo e pode ser aproximado das observações de Trindade: o temor da concorrência feminina nos mercados de trabalho situação que os resultados dos Editais das Universidades já sugeriam quinze anos atrás:

Em toda parte, no comércio, na indústria, no funcionalismo público ou não, por todos os cantos se mete a mulher evoluída. O que acontece com isso? Os homens vão sendo desbancados nos empregos e são lesados os próprios pais, os próprios irmãos da costela que progride ou julga 


$$
\text { progredir. (TRINDADE, 1996, p. 86). }{ }^{10}
$$

Depois de abordar a profissionalização feminina e sua inserção no mercado de trabalho, o jornal aponta a colaboração da mulher no campo científico. $\mathrm{O}$ aspecto mais importante nessa área refere-se principalmente ao da educação. Ou seja, a mulher ocuparia expansivamente e predominantemente a função de professora. Aliás, essa era uma das funções destinadas às mulheres de Ponta Grossa, como afirmou Annita Philipowiski na introdução deste tópico. Sobre esta questão,

A colaboração da mulher na educação da mocidade é preciosa no terreno da pedagogia moderna. $\mathrm{O}$ ensino das crianças é uma especialidade em que domina soberana a mulher, na escola de hoje. Vencidos os preconceitos estúpidos que se opõem á educação conjunta dos sexos, a emulação nascida do trabalho em comum, no mesmo salão, sobre as mesmas provas, redunda em benefícios incalculáveis para ambas as frações da humanidade. (O PROGRESSO, ed. 276, 23 jun.1910).

Percebemos que pelo discurso do jornal timidamente surgia uma mulher que transpunha os limites de sociabilidade doméstica. Após destacar o papel eficiente e importante da mulher no campo do ensino, o autor conclui o texto: "no futuro, compreendendo-se melhor, mais aptos para uma colaboração inteligente, bem aparelhados com melhores recursos para o domínio da natureza inconsciente, ao crepúsculo matinal de uma nova era [...]." (O PROGRESSO, ed. 276, 23 jun. 1910). Essa nova era, preconizada pelo jornalista, seria a de plena colaboração entre homens e mulheres, de certa forma favorável ao desenvolvimento material e intelectual da sociedade.

Nesta passagem é preciso que contextualizemos a função da mulher educadora, a qual está presente nos propósitos republicanos de educação popular. "É o sonho da República espalhando a instrução, democratizando a sociedade para formar o cidadão cívica e moralmente e colaborar para que o Brasil se transforme em uma nação à altura das mais progressistas do século." (TRINDADE, 1996, p. 163).

Ao analisar as imagens das escolas e as fotos dos docentes que nelas lecionavam, Rosa Fátima de Souza reafirma a superioridade feminina no magistério. "O grande número de mulheres em relação ao reduzido número de professores do sexo masculino registra o que foi a composição do magistério primário no Brasil do final do século XIX." (SOUZA, 2001, p. 92). E podemos acrescentar expansivamente no início do século XX.

Na seção "Notas Pedagógicas", transcritas de artigo veiculado no jornal O Estado de São Paulo, o jornal critica o ensino normal:

Neste ponto devemos acrescentar que o ensino normal no Brasil é uma burla completa. As escolas denominadas 'normais' não passam de estabelecimentos de ensino secundário, sujeitos ao mesmo regimento anarquizado e ao mesmo tempo pessoal incapaz dos demais. A aprendizagem profissional, teórica e pratica, está geralmente descurada, sendo a pedagogia lecionada num só ano com esquecimento da metodologia. De resto não apresentam nenhum fim educativo nacional, tendendo a desenvolver-se no espírito do futuro mestre a consciência das suas funções na constituição de uma nacionalidade forte, próspera e culta. Acresce que o programa de tais escolas não atende as necessidades de um povo que, soube obedecer a influencias de um meio selvagem, precisa renovar seus métodos de trabalho, incompatíveis com a sociedade hodierna.(O PROGRESSO, ed. 277, 25 jun. 1910). 
Na passagem acima o autor assume um posicionamento crítico em relação à Escola Normal. Ela, que antes foi implantada como um modelo básico de formação, apresentavase com muitas deficiências. Mas como solucionar o problema? Na mesma seção de "Notas Pedagógicas", agora no $\mathrm{n}^{\mathrm{o}} 284$ de 12 jul. 1910, no artigo intitulado "O Ensino Normal em S. Paulo de 1810 até a presente necessidade de organizá-lo sem mais demora", o autor volta a referir-se ao problema do ensino normal no Estado de São Paulo. A falta de medidas urgentes para a melhora na educação implicaria em deficiências muito grandes para o futuro. Se não houvesse investimentos na educação, tais deficiências se tornariam maiores ainda.

Com relação aos professores, o autor do artigo destaca dois tipos: o primeiro ele chama de professor complementarista; o segundo de normalista. Além de apontar esta nomenclatura, o autor preocupa-se em analisar as distinções entre ambos. Os complementaristas "são professores toleráveis somente na analfabetolandia, onde até as leis parecem de analfabetos". (O PROGRESSO, ed. 284 de 12 jul. 1910). Percebe-se uma crítica aberta a este tipo de professor, quando há a afirmação de que não são municiados pelas doutrinas pedagógicas, bem como que essas lacunas condizem com a consequiente falta de instrução dos alunos, que geralmente permanecem analfabetos.

Os normalistas, apesar de uma semântica distinta, não têm um significado propositivamente favorável. "[...] Eles não satisfazem melhor as boas normas pedagógicas." (O PROGRESSO, ed. 284 de 12 jul. 1910). Com uma série de argumentações, o autor visibiliza a educação normal como deficitária. Para explicar essa deficiência, busca-se um retrospecto histórico que antecede a proclamação da República:

Meses depois de proclamada a Republica, verificou-se o primeiro esforço para amoldar o ensino normal aos seus verdadeiros fins profissionais. Reclamou essa 'grande reforma', que 'havia de nos dar a escola nacional capaz de incutir no animo popular o sentimento da pátria moderna', esta mesma folha, pela pena de um velho mestre - Rangel Pestana ${ }^{11}$. Foi então que o governador Prudente de Moraes encarregou esse seu amigo e companheiro de organizar os planos postos em vigor pelo decreto de 12 de março de 1890, 'reformando a Escola Normal e convertendo em escolas-modelos as escolas anexas (O PROGRESSO, ed. 284 de 12 jul. 1910).

Segundo Leonor Maria Tanuri a primeira Escola Normal Brasileira foi fundada no Estado do Rio de Janeiro em 1835 e sua estabilização só aconteceria no final do século XIX e expansão no início do século XX. (TANURI, 2000). Por isso a dicotomização entre complementaristas e normalistas presente no discurso do jornal. Rosa Fátima de Souza afirma que "o curso complementar, também com duração de quatro anos, destinava-se inicialmente aos alunos habilitados do curso preliminar, e deveria ser ministrado em escolas complementares. Souza continuando aponta que

Esse $2^{\circ}$ grau do curso primário logo foi descaracterizado como tal, sendo transformado, a partir de 1895, em escolas para formação de professores preliminares. Até serem transformadas, em 1911, em escolas normais primárias, as escolas complementares foram efetivamente as responsáveis pela formação do magistério primário (SOUZA, 1998, p. 44).

$\mathrm{Na}$ visão do jornalista, nem a escola complementar, nem a escola normal eram 
capazes de formar profissionais condizentes com um ensino de qualidade para o povo brasileiro. Mesmo assim, o autor do texto arrisca-se a afirmar que a reforma da educação do Estado de São Paulo e a reformulação da Escola Normal trariam novas perspectivas para a instrução pública.

Em ed. 291, de 28 de julho de 1910, na mesma seção Notas Pedagógicas, ao referenciar o ensino normal, afirma-se que "o ensino em tais escolas seja simplesmente profissional." Por esse motivo, o autor conclui a seção apontando que "em nosso caso, seria exigir como base do ensino normal um curso secundário nos ginásios, divididos em dois ciclos, um realístico e outro clássico [...]." No $\mathrm{n}^{\mathrm{o}} 292$, de 30 de julho de 1910, há a indicação de que "[...] a principal disciplina a lecionar seria a pedagogia, abrangendo a teoria prática e a crítica." Segundo o autor, "por teoria pedagógica não compreendemos certas futilidades sobre a existência de uma ciência ou arte de educar, a vantagem ou desvantagem da educação, as infinitas divisões desta, etc.", mas sim

[...] a evolução das doutrinas pedagógicas através dos séculos, e vida exemplar dos grandes pedagogos em busca do aperfeiçoamento humano, a comparação dos sistemas educativos dos vários países, a exposição da metodologia moderna, em fim, tudo quanto em todas as nações ilumina o cérebro, forja a alma e guia o esforço do verdadeiro mestre, que não é mais um produto do empirismo. (O PROGRESSO, ed. 292 de 30 jul. 1910).

A educação da mulher teve um destaque relativo nas páginas do Diário dos Campos. Primeiramente, ela aparece como necessidade da mulher educar seus filhos. Posteriormente, este periódico sustenta a tese da inserção da mulher no mercado de trabalho. Primeiro, ela ocupa o comércio e as funções de modo geral. Depois, o que passa a prevalecer é a função da mulher educadora. Nesse contexto, exige-se a implantação da Escola Normal e ao mesmo tempo o discurso do jornal passa a questionar as suas deficiências.

\section{Escolas modernas, pedagogia moderna}

No que se refere aos desejos de reformas, tendo com pressuposto as discussões da pedagogia moderna, iniciamos nossa análise no pensamento educativo de Rui Barbosa. Na edição 250, de 20/01/1910, uma coluna do jornal apresenta esse intelectual na reprodução de um documento denominado a plataforma:

A plataforma do Sr. Ruy Barbosa é um documento político, que a força de uma lógica irredutível esmaga a protervia, e falando bem alto à Nação mostra o que Ela deve ser no futuro, deixando após si esse amontuado de erros e de crimes perpetrado à sombra de uma Constituição, rasgada desde os seus primeiros dias de existência.

Neste documento, explicita-se a necessidade da reformulação da Constituição Federal: "continuamos a suma deste documento político, que passará ao arquivo da história como um código inestimável de grande civismo; vamos citando o que diz o Dr. Ruy Barbosa sobre o código civil". No texto é feita uma breve análise do debate envolvendo a formulação do código de ensino brasileiro. A principal questão debatida é sobre a instrução pública: 
Falta de instrução pública, que tem ideias amplamente desenvolvidas sobre o assunto. Os governos entre nós reformam os mecanismos e nenhum busca reformar os costumes. Temos tido códigos de ensino cheios de respeito e de excelentes disposições, mas quase que unicamente para dar pasto ao arbítrio da administração. A instrução publica entre nós carece continuidade na observância da lei, efetividade na distribuição do ensino; realidade no exercício da fiscalização, especialmente no que diz respeito aos colégios equiparados, livres e faculdades livres. São trivialidades cada uma das quais denuncia uma lacuna fatal na educação do paiz e que se não se mantiver em letra morta se reabilitará. (O PROGRESSO, ed. n 252, de 25 jan. 1910).

Nessa passagem percebemos como temática central aspectos relacionados às reformas educacionais. No centro das discussões estavam presentes as ideias de Rui Barbosa. A instrução pública foi questão constante no seu pensamento. Maria Cristina Gomes Machado afirma que "no conjunto da sua obra, a educação ocupa lugar importante, mas num espaço de tempo muito curto (1881-1883).” (MACHADO, 2002, p. 29). Entre as reformas preconizadas por Rui Barbosa, merece destaque a da educação. O século XIX foi o "século que difundiu a instrução pública, e Rui Barbosa foi influenciado pelas discussões da época, tanto que, empenhado num projeto de modernização do país, se interessou pela criação de um sistema nacional de ensino, desde o jardim de infância até a universidade." (p. 109).

Olhando para o posicionamento desta autora, parece um discurso deslocado, mas o fato é que como redator do jornal, Hugo de Borja Reis participou explicitamente da campanha Civilista da Candidatura de Rui Barbosa ${ }^{12}$, a presidente da Republica. Segundo Alexandra Perrichelli Bucholdz, essa campanha "[...] significava para ele uma real possibilidade de pôr fim à política do café com leite." (BUCHOLDZ, 2007, p. 32). Daí a justificava, da transcrição nas páginas do jornal Diário dos Campos, das idéias educativas de Rui Barbosa.

No mesmo texto, ainda são trazidos alguns pontos relacionados ao melhoramento da educação.

Indica: $1^{\circ}$ o melhor método do ensino secundário nos estabelecimentos federaes; $2^{\circ}$ a remodelação do ensino jurídico, obedecendo às normas que lhe dêem a um tempo extensão prática e mais espírito cientifico; $3^{\circ} \mathrm{o}$ desenvolvimento dos gabinetes, laboratórios, clínicos e estudos práticos nas escolas de medicina; $4^{\circ}$ a mantença rigorosa da freqüência escolar; $5^{\circ}$ obrigação de uma Universidade no Rio de Janeiro, aproveitando as universidades ali já existentes segundo o tipo universitário da Alemanha. (O PROGRESSO, ed. $n^{\circ} 252$, de 25 jan. 1910).

Os pontos acima citados representavam Rui Barbosa como um homem que buscava inspiração externa para a reformulação da educação brasileira, tendo como base o ensino superior. $\mathrm{Na}$ época da sua proposta de reforma para este nível de educação, o ensino brasileiro "[...] encontrava constituído por duas faculdades de direito, duas de medicina, uma escola de marinha, uma escola prática de artilharia de marinha, uma escola militar, uma escola politécnica e uma escola de minas." (NASCIMENTO, 1997, p. 30).

Outra questão presente no discurso do jornal refere-se à reformulação metodológica. Em artigo publicado em 01 de out. 1921, questiona o porquê do não desenvolvimento do Brasil:

[...] os homens que têm a responsabilidade da instrução em nossa pátria, 
ainda não puderam descobrir a forma pratica e eficaz de disseminá-la pelas suas campanhas, pelos seus sertões extensos e abandonados dos carinhos dos governos [...] Se falta metodologia de ensino, falta também uma maior ação do governo nos locais mais distantes e isolados do país. (DIÁRIO DOS CAMPOS, ed. 2897, 01 out. 1921).

Uma das deficiências apontadas nesse texto resultou da inspiração, principalmente em nível primário que os nossos educadores buscavam em outras nações.

Julga-se que os métodos que dão resultados satisfatórios na Europa não devem ser adotados aqui, sem se cogitar das nossas condições étnicas, das diversidades do nosso clima, da precocidade da nossa infância, duma porção de agentes que nos põem em plana diametralmente oposta aos europeus. (DIÁRIO DOS CAMPOS, ed. 2897, 01 out. 1921).

Nesse raciocínio, diagnosticava-se a necessidade de formular uma educação nacional que fosse compatível com as condições geográficas, econômicas e raciais do Brasil. Reforçando o texto transcrito em o "Paiz", o autor critica que esta educação "estrangeira" é aplicada apenas nas grandes capitais. O resto do território brasileiro, isolado, fica esquecido, e nos locais mais distantes é onde se concentra o mais alto índice de analfabetismo brasileiro. Na visão do autor, tem bons resultados na Europa, porque essa instrução está integrada à cultura da sociedade. Sendo assim, pais e mães, já instruídos pelo mesmo sistema, têm condições de educar seus filhos. Comparativamente, as mães do Brasil não receberam mínimas instruções que lhes dessem condições para orientar seus filhos. Para isso, no Brasil, "a escola primária deve ter um prolongamento do lar e não um centro pedantesco de conhecimentos dispares e disparatados." (DIÁRIO DOS CAMPOS, ed. 2897, 01 out. 1921).

Este debate em relação à educação brasileira, tendo como fundamentação as reformas européias e latino-americanas, está inserido nos princípios republicanos de educação laica, pública e gratuita. Na década de 1890, o fator de maior repercussão educacional foi a reforma da instrução pública do Estado de São Paulo. Seguindo os ideais de reforma popular republicana, deu-se ênfase à escola primária, cujo principal fator de reformulação foi a implantação dos grupos escolares, em que a Escola Normal teve atenção redobrada pelos reformadores paulistas, seus iniciadores. A ideia já pensada por Rui Barbosa era a "reforma dos métodos e reforma do mestre: eis uma expressão completa, a reforma escolar inteira." (SOUZA, 1998, p. 39). E Souza afirma ainda que "os reformadores acreditavam na imprescindibilidade da formação dos professores para a renovação da escola pública." (p. 40). Nessas condições, "ser professor passa a pressupor um profissional atualizado, estudioso, dinâmico.” (p. 206).

Além das reformas educacionais em nível nacional o discurso do jornal esteve sintonizado com a educação no Estado do Paraná. No texto intitulado "O ensino primário no Paraná", edição 2920 de 07 de novembro de 1921, percebemos um discurso centralizado na figura de Caetano Munhoz da Rocha. O autor introduz dessa maneira: "com verdadeira satisfação veremos o grande impulso, que o ensino primário do Paraná, está dando o benemérito do governador Sr. dr. Caetano Munhoz da Rocha." E com relação ao governador, o texto é enfático:

Homem de ação, homem prático, o Sr. Presidente do Estado soube organizar a complicada maquina da instrução, abole abusos, aperfeiçoando métodos, de forma que já se pode presenciar o real progresso obtido em tempo relativamente curto. E não digamos só na 
parte parcial do Estado. Excia. atende os benefícios do ensino; em todas as localidades, todos os municípios, cidades, vilas, povoados estão recebendo o influxo do magnífico programa abrem-se escolas espalham se professores por todos os recantos da nossa terra, e ação segura e criteriosa do governo, segurando a necessária confiança estimula os paes que mandam os filhos á escola, na certeza de que assim procedendo asseguram á sua prole o quinhão do preparo indispensável que facilita a existência, quando crescem na grande concorrência, "struggle for lifes". ${ }^{13}$ (DIÁRIOS DOS CAMPOS, ed. 2920, 07 nov. 1921).

No discurso do jornal, as transformações educacionais estavam associadas ao governo de Caetano Munhoz da Rocha: "o esforço do dr. Munhoz da Rocha, convergido inteiro para o problema da instrução, vai a golpes gigantescos desbastando a selva escura da ignorância, abrindo clareiras gloriosas, que nos vão libertando desse povo repelente." $\mathrm{Na}$ conclusão o autor salienta que o ensino do Paraná, passou a ser referência a partir de Caetano Munhoz da Rocha, nos jornais da Capital Federal e outros Estados da União. As reformas preconizadas por Caetano Munhoz da Rocha, através da atuação do inspetor de instrução pública do Paraná, César Prieto Martinez, fizeram, por consequência da sua aplicação no Estado, o Brasil se tornar o segundo país a empreender reformas educacionais renovadoras. É importante observar que a Escola de Formação de Professoras foi estabelecida em Ponta Grossa na década de 1920, no governo de Munhoz da Rocha, o que constituiu-se ao grupo do jornal como principal símbolo da educação pública na cidade.

A partir de Carlos Eduardo Vieira e Aurélio Bona Junior (2007, p. 18), percebemos que no Estado "o discurso da modernidade seduziu corações e mentes, mas também provocou apreensão e resistência." O culto ao novo e ao moderno mostrou-se associado ao temor de desestabilização dos valores e das normas de convivências social. Na concepção, "[...] a retórica reformista dos intelectuais engendrou o discurso da modernidade que tinha no tema da formação um dos seus pontos arquimedianos." (p. 33).

A nota "Bases educativas para a organização da nova escola normal secundária do Paraná" ed. 3.316 apresenta Lyzímaco Ferreira da Costa:

Sentimo-nos felizes quando se nos apresenta ocasião propicia de registrar a satisfação e o orgulho, que nos enchem a alma, pela afirmação brilhante dum talento que eleva o nível intelectual do Estado e o faz admirado la fora, como no caso magnífico desse modesto paranaense Lysimaco Ferreira da Costa, que pela inteligência, superiormente cultivada, é um ponto de irradiação no seio das verdadeiras competências da atualidade. Lutador de fibra, Lysimaco vem conquistando, em surtos extraordinários, os mais alcandorados postos do saber, trabalhando concomitantemente, para o bom nome intelectual do seu Estado.

Jean Carlos Moreno (2007) estuda a atuação de Prieto Martines e Lyzímaco da Costa que, durante a década de 20, trabalharam na Inspetoria da Instrução Pública do Paraná (1920-1928). Moreno mostra esse novo ideal educativo do Estado. O autor parte do pressuposto de que no governo de Caetano Munhoz da Rocha (1920-1928) buscava-se introduzir no Estado um novo modelo de educação. Logo que assumiu o governo, Rocha incumbiu Lysímaco Ferreira da Costa, para ir a São Paulo convidar um profissional da educação para vir ao Paraná, uma vez que a educação paulista havia passado por profundas reformas. Lysímaco trouxe o educador César Prieto Martinez, que "assumiu a inspetoria de educação do Paraná no período de 1920-1924.” (p. 41).

Moreno demonstra que a quantidade de escolas multiplica-se no Estado do Paraná 
no primeiro governo de Caetano Munhoz da Rocha e do inspetor educacional Cesar Prieto Martinez. Mas no geral, apesar de significativa desenvoltura, o que se nota é que é dada mais atenção aos núcleos urbanos e à capital. $\mathrm{O}$ discurso que move esses educadores é "a crença na educação como redentora da nação e até como possibilidade de instauração de um novo mundo [...]." (p. 45). Sonha-se, inclusive, com a intenção de instaurar uma nova sociabilidade pautada pela civilidade, desvelando uma das principais faces da apropriação da modernidade realizada por esses intelectuais. A conclusão do autor é de que apesar de não atingirem todos seus objetivos, de forma geral os inspetores Prieto Martinez e Lysímaco Ferreira da Costa conseguiram transformar o quadro educacional no Paraná. Sonhavam em modernizar a escola e com ela modernizar a sociedade. $\mathrm{O}$ desejo de ambos era mudar o hábito da população rumo ao engajamento e à construção de um espírito de nação.

A educação local também esteve presente no discurso do jornal. Em artigo intitulado "A Instrução em Ponta Grossa", ed. 1.553 de 31 de janeiro de 1916 do Diário dos Campos, notaram-se comentários relacionados à educação da cidade.

Ponta Grossa é uma cidade bastante desenvolvida, com uma população de quase doze mil habitantes, podia já possuir não só uma escola de segundo grau como também um estabelecimento de ensino superior secundário. Pois, para isso ela possui não somente população suficiente como também um clima adorável, panoramas belíssimos, onde a vista se expande em contemplações de policromicas paisagens, onde o sangue se vitalisa e se rejuvenesce, - proporcionando saúde e vigor. Quanto a Instrução publica primária, apesar da incontestável boa vontade e competência do Sr. Inspetor Escolar, de alguma melhoria se recente. Não, em absoluto, quanto a instrução feminina, - essa está suficientemente disseminada, tendo à frente preceptoras mui capazes e distinctas; somente enquanto a instrução masculina é que me refiro; esta, para uma população tão numerosa, conta apenas com três escolas, sendo duas reunidas em Semi Grupo e somente uma isolada! É como vemos, demasiadamente insuficiente o número de escolas masculinas para esta cidade. Era, pois de justiça que se criasse mais uma escola masculina aqui.

Desde o final do século XIX foram implantados na cidade grupos e colégios. Segundo Niltonci Batista Chaves esses colégios foram "particulares, públicos, religiosos, profissionalizantes, comunitários, seja qual for a origem e a função dos estabelecimentos, a cidade contava com uma considerável quantidade deles. (2001, p. 70). No Paraná, o desenvolvimento do ensino processou-se lentamente. O Ensino Primário, tanto no Estado como em Ponta Grossa, seguiu os parâmetros da política educacional brasileira e paranaense.

Ponta Grossa vê instalada o seu primeiro Grupo Escolar no início da década de 1910. Esse primeiro grupo escolar recebeu o nome de Casa Escolar Senador Correa. Outros colégios importantes na rede pública de ensino só viriam a ser inaugurados em meados da década de 1920 (Escola de Formação de Professores e Colégio Regente Feijó).

Os intelectuais do jornal filtraram e puseram em discussão o debate educativo nacional, por meio do qual puseram na pauta os problemas da sociedade e da educação paranaense. Estes intelectuais sistematizaram nas primeiras décadas do século XX, um debate compatível com as principais discussões educativas relacionadas ao povo brasileiro, no qual foram utilizados, além de seus próprios posicionamentos, textos transcritos de artigos de jornais de circulação nacional. 


\section{À guisa de conclusão}

No desenvolvimento deste artigo nos preocupamos em analisar o discurso dos intelectuais do jornal Diário dos Campos sobre educação no período de 1907 a 1928 , privilegiando as intervenções de Jacob Holzmann, Hugo Mendes de Borja Reis e José Cadilhe. Esses intelectuais atuaram no processo de organização e de transmissão de visões de mundo que visavam formar uma identidade nacional, bem como constituir um novo ethos na cidade de Ponta Grossa.

Pela análise feita foi possível perceber que os intelectuais do jornal pesquisado estavam sintonizados aos discursos sobre educação que se desenvolveram nos primeiros anos do século XX e é possível sustentar que o jornal foi um importante veículo de divulgação de discussões relacionadas à educação. Nessa afirmação ressaltamos dois aspectos. O primeiro está relacionado aos intelectuais do jornal; o segundo ao discurso sobre educação que foi veiculado através dele.

Com relação ao primeiro aspecto, ficou evidenciado que a minoria dos artigos veiculados pelo jornal foi assinada pelos intelectuais que analisamos. No entanto, como foram editores ou proprietários do jornal defendemos a hipótese de que tiveram autonomia para autorizar a divulgação desses textos. Um fator marcante em relação a esses intelectuais diz respeito ao caráter eclético de Hugo Reis que, além de chefiar o jornal, publicou artigos defendendo a educação ou argumentado sobre ela. Na realidade, Hugo Reis ao inserir a imprensa como o quarto poder constituído, afirmava ser responsabilidade de ela lançar a cruzada contra o analfabetismo. Sua posição defendida era o de ver um povo culto e educado. Jacob Holzmann e José Cadilhe não escreveram artigos que tratassem especificamente da educação, mas estiveram comprometidos com a organização e disseminação de novas maneiras de pensar ao coordenarem as atividades editoriais do jornal.

No que diz respeito ao discurso sobre educação no jornal Diário dos Campos, evidencia-se a hipótese de que os intelectuais do referido periódico estavam sintonizados aos debates educativos travados nas principais cidades brasileiras. A rigor, no período investigado, a educação foi uma temática recorrente no discurso do jornal. A preocupação com a formação do povo apresentava temáticas mais específicas, entre as quais se destacavam a noção de educação como salvadora da nação, a tese da educação feminina e formação de professor, bem como a defesa de reformas educativas.

Estava presente no discurso do jornal o caráter salvacionista da educação, pois ao associar a criminalidade a um problema social, na sequência era postulada a assertiva da educação como remédio para curar esse mal. Por isso, os intelectuais do jornal se voltaram contra o analfabetismo, uma vez que a ele era atrelada a desagregação social. Se a educação era fator de salvação, era preciso que se lutasse por ela. Trata-se de uma tendência reformadora que teve como paradigma os ideais republicanos, e que foi impulsionada, sobretudo, pela reforma da instrução pública efetivada em São Paulo no início da década de 90 do século XIX. Parcela significativa da intelectualidade brasileira daquele período viu na educação um modo de promover a formação da nacionalidade por intermédio de uma cultura nacional e de uma educação moral sólida que assegurassem o progresso da civilização.

Em síntese, os intelectuais do jornal pesquisado atribuíram relevância à causa educacional, e ao promoverem a discussão sobre os problemas societários, os elegeram a questão educacional como temática relevante. O discurso educacional presente neste periódico estava sintonizado ao debate que circulava nas principais cidades brasileiras. A rigor, enunciava os problemas do analfabetismo, da educação feminina, da 
profissionalização da mulher (professora/educadora) e das reformas educativas.

\section{FONTES}

Jornal O Progresso (1907-1913)

Jornal Diário Dos Campos (1913-1924)

BUCHOLDZ, Alexandra Perrichelli. Diário dos Campos: memórias de um jornal centenário. Ponta Grossa, Editora UEPG, 2007.

HOLZMANN, Epaminondas. Cinco Histórias Convergentes. $2^{\text {a }}$ ed. revisada. Ponta Grossa, Editora UEPG, 2004.

\section{Referências}

BAKHTIN, Mikhail. (VOLOSHINOV). Marxismo e filosofia da linguagem: problemas fundamentais do método sociológico na ciência da linguagem. São Paulo: Ed. Annablume, 2002.

CARVALHO, Marta Maria Chagas. Molde nacional e fôrma cívica (1924-1931). Bragança Paulista: Edusf, 1998.

CHAVES, Niltonci B. (org.). Visões de Ponta Grossa. Ponta Grossa: Editora UEPG, 2001.

ELUTÉRIO, Maria Lurdes. Imprensa a serviço do progresso. In: MARTINS, Ana Luíza; LUCA, Tânia Regina de (Org.) História da imprensa no Brasil. São Paulo: Contexto, 2008.

GRAMSCI, Antonio. Cadernos do cárcere, vol. 02. Rio de Janeiro: Civilização Brasileira, 2006.

JÚNIOR, Aurélio Bona; VIEIRA, Carlos Eduardo. O discurso da modernidade nas conferências educacionais na década de 1920 no Paraná. In: VIEIRA, Carlos Eduardo (org.). Intelectuais, educação e modernidade no Paraná (1886-1964). Curitiba: Ed. UFPR, 2007, p. 13-40.

LUCA, Tânia Regina de. História dos, nos e por meio dos periódicos. In: PINSKY, Carla Bassanezi (org.). Fontes Históricas. São Paulo: Contexto, 2005. p. 111-153.

MACHADO, Maria Cristina Gomes. Rui Barbosa: pensamento e ação. Campinas, SP: Ed. Autores Associados, 2002.

MARTINS, Ana Luisa; LUCA, Tânia Regina de (org.) História da imprensa no Brasil. São Paulo: Contexto 2008.

MONARCHA, Carlos. Escola normal da praça: o lado noturno das luzes. Campinas, SP: Ed. Da Unicamp, 1999.

MORENO, Jean Carlos. Intelectuais na década de 1920: César Prieto Martinez e Lysímaco Ferreira da Costa à frente da instrução pública no Paraná. In: VIEIRA, Carlos Eduardo (Org.). Intelectuais, educação e modernidade no Paraná (1886-1964). Curitiba: Ed. UFPR, 2007, p. 41-64.

NASCIMENTO, Teresinha A. Quaiotti Ribeiro. Pedagogia liberal modernizadora. Campinas, SP: Autores Associados, 1997.

SILVA, Helenice Rodrigues. História Intelectual: horizontes teóricos. In: LOPES, Marco Antonio (Org.). Grandes nomes da história intelectual. São Paulo: Contexto, 2003. p. 
$15-24$.

SOUZA, Rosa Fátima de. Fotografias escolares: a leitura de imagens na história da escola primária. Educar, Curitiba, n. 18, p. 75-101. 2001. Editora da UFPR.

SOUZA, Rosa Fátima de. Templos de civilização: a implantação da escola primária graduada no Estado de São Paulo. São Paulo: Fundação Editora da Unesp, 1998.

TANURI, Leonor Maria. História da Formação de Professores. Revista Brasileira de Educação, 2000, p. 61-80.

TRINDADE, Etelvina Maria de Castro. Clotildes ou Marias: mulheres de Curitiba na primeira república. Curitiba: Farol do Saber, 1996.

VIEIRA, Carlos Eduardo. Intelectuais, educação e modernidade no Paraná (18861964). Curitiba: Ed. UFPR, 2007.

VIEIRA, Carlos Eduardo. Jornal diário como fonte e como tema para a pesquisa em história da Educação: um estudo da relação entre imprensa, intelectuais e modernidade nos anos de 1920. In: OLIVEIRA, Marcus Taborba de. Cinco estudos em história e historiografia da Educação. $1^{\text {a }}$ ed., Belo Horizonte: Autêntica Editora, 2007b, v. 1, p. 11 40 .

Notas

\footnotetext{
${ }^{1}$ Mestre em Educação e Especialista em História e Cultura pela Universidade Estadual de Ponta Grossa.

${ }^{2}$ Professor do Programa de Mestrado e Doutorado em Educação da Universidade Estadual de Ponta Grossa.

${ }^{3}$ Diário dos Campos é o segundo nome dado ao jornal, que foi fundado em 1907 como o nome de $O$ Progresso. Porém, levando em consideração o fator longevidade (desde 1913 até hoje é Diário dos Campos), utilizaremos esta denominação no título, bem como em muitas passagens do texto.
}

${ }^{4}$ Em 1879, Juca de Godói fundou a banda Lira dos Campos. A principio Holzmann atuava como membro da referida banda. Em 1896, quando Godói sentia o peso da idade, Jacob Holzmann assumiu em definitivo sua coordenação e atuou como Maestro até o final da década de 20 quando a era das bandas de música chega ao fim em Ponta Grossa, por força das transformações sociais, que também encerou o ciclo empreendedor de Jacob Holzmann.

\footnotetext{
5 A primeira geração é a dos fundadores, Marc Bloch e Lucien Febvre, responsáveis pelo lançamento da revista Annales de "historie économique et sociale (1929). Em 1956, com a morte de Febvre, Fernand Braudel tornou-se o diretor efetivo dos Annales e ocupou lugar dos mais destacados na historiografia e no sistema universitário francês até sua aposentadoria em 1972, tendo ao seu lado nomes como Ernest Labrousse e Emmanuel Le Roy Ladurie. A terceira geração compõe-se de ampla plêiade de historiadores entre os quais estão François Furet, Georges Duby, Jacques Le Goff, Jacques Revel, Michèle Perrot, Mona Ozouf e Pierre Nora. (LUCA, 2005)

${ }^{6}$ Este texto é assinado por Guerra Junqueiro, mas o jornal não trás nenhuma especificação em relação ao autor.

${ }^{7}$ Ferro de marcar gado, criminosos, escravos. Sentido figurado: ignomínia.

${ }^{8}$ Nasceu em Ponta Grossa em 1886. Filha de fazendeiro e morando no meio rural sua educação se processou por meio de professores contratados. No entanto, a partir de 1910 ela começa a se destacar como contista, novelista e poeta. Teve uma participação significativa no jornal Diário dos Campos onde várias de suas crônicas foram publicadas.
} 


\footnotetext{
${ }^{9}$ Foi criado em 1906 pelo Dr. João Cândido Ferreira. Tratava-se de um Instituto Comercial/ particular, com subvenção do Governo. As disciplinas, ali ministradas, incluíam os estudos de línguas portuguesa, francesa e alemã, geografia, aritmética, geometria, história do Brasil e escrituração mercantil.

${ }^{10}$ Retirado de Diário da Tarde de Curitiba, 01 de março de 1929.

${ }^{11}$ Francisco Rangel Pestana nasceu em Nova Iguaçu em 26 de novembro de 1839 e faleceu em São Paulo, em 17 de março de 1903. Foi jornalista e político brasileiro. Signatário do Manifesto Republicano (1870), foi deputado da província de São Paulo em diversas legislaturas e, proclamada a República, assumiu a direção da província no triunvirato em que também faziam parte Prudente de Morais e o coronel Joaquim de Sousa Mursa. Em 1890, foi eleito senador, cargo que exerceu até 1896.

${ }^{12}$ A convenção realizada em 3 de outubro de 1909, no teatro Lírico, na Bahia, lançava a candidatura de Rui Barbosa à Presidência da República.

${ }^{13}$ Expressão inglesa que significa "luta pela vida".
}

Recebido em: $\quad 04 / 01 / 11$

Aprovado em: $\quad 24 / 02 / 11$ 